\title{
An academic and free clinic partnership to develop a sustainable rural training and clinical practice site for the education of undergraduate and advanced practice nurses
}

\author{
Audrey E. Snyder ${ }^{* 1,2}$, Gwyneth Milbrath ${ }^{1}$, Teresa Gardner ${ }^{3}$, Paula Meade ${ }^{3}$, Elizabeth L. McGarvey ${ }^{4}$ \\ ${ }^{1}$ School of Nursing, University of Virginia, Charlottesville, Virginia, United States \\ ${ }^{2}$ School of Nursing, University of Northern Colorado, Greeley, Colorado, United States \\ ${ }^{3}$ The Health Wagon Free Clinic, Clintwood, Virginia, United States \\ ${ }^{4}$ School of Medicine, University of Virginia, Charlottesville, Virginia, United States
}

Received: October 8, 2014

DOI: $10.5430 /$ jnep.v5n4p7
Accepted: January 4, $2015 \quad$ Online Published: January 18, 2015

URL: http://dx.doi.org/10.5430/jnep.v5n4p7

\begin{abstract}
The purpose of this project was: 1) to expand clinical training experiences for undergraduate, graduate and advanced practice nursing students at a rural free clinic, 2) to test the feasibility of developing a model training and practice internship for undergraduate, graduate and advanced-practice nurses as part of a Health Resources and Service Administration (HRSA)-funded academic-community partnership to encourage nurses to consider future employment in rural Appalachia and 3) to determine the successes and challenges of this endeavor. This paper reports the successes and challenges of this partnership. Data were collected from nursing students attending the University of Virginia through self-reported student information forms. A total of 145 students (56 advanced practice, 19 graduate and 70 undergraduate nursing students) successfully received scheduled clinical training experiences at three rural clinic sites operated by the Health Wagon (HW), a free clinic in rural Southwest Virginia. It is feasible to develop and implement a long distance academic and community-based partnership to provide real life experiences for undergraduate, graduate and advance practice nurses, including nurse practitioners, in rural settings. Success depends on the commitment of both the academic and free clinic staff to the program, excellent on-site clinical supervision of students, and a source of revenue to cover both on-site and travel related expenses for students and preceptors.
\end{abstract}

Key Words: Nurse managed clinic, Nurse practitioner, Rural, Students, Education

\section{Introduction}

Nurse managed health clinics (NMHC) are safety net providers that effectively provide care to the nation's most vulnerable populations. ${ }^{[1,2]}$ While some nurse managed health clinics function within nursing schools, others are independently operated by nurse practitioners. Primary care nurse practitioners practicing in NMHCs and free clinics often are those who provide this care in the United States. ${ }^{[3]}$

Approximately two-thirds of all rural and remote health care is delivered by a relatively small number of nurses, with advanced practice nurses often operating free clinics and NMHCs. ${ }^{[4]}$ Within the U.S. Health Resources and Services

\footnotetext{
*Correspondence: Audrey E. Snyder; Email: aew3e@virginia.edu; Address: University of Northern Colorado, Gunter Hall, Campus Box 125, Greeley CO 80639, United States.
} 
Administration (HRSA) is the Bureau of Health Professions, which works to improve access to health care across the country, ensuring the highest quality of care is available to those living in both urban and rural areas. In addition, national leaders have prioritized developing and recruiting culturally diverse, well-trained, adaptable healthcare professionals who can meet the needs of the ever changing population.

With funds from the Affordable Care Act distributed by the Bureau of Health Professions, the Health Wagon, a 501(3)c free mobile clinic, was awarded a three-year grant in collaboration with the University of Virginia in Charlottesville, Virginia (UVA). Clinical sites were located in rural southwest Virginia, over three hundred miles away from UVA, in conjunction with the University of Virginia's College at Wise (UVA Wise), and other community partners in the area.

The Health Wagon visits eleven sites in six counties, which are federally designated Health Professional Shortage Areas and Medically Underserved Areas. In this service area, $43 \%$ of the population is below $200 \%$ of the federal poverty level, and $16 \%$ of residents are uninsured. ${ }^{[5,6]}$ In 2014, the Robert Wood Johnson Foundation ranked the six counties in the Health Wagon's catchment area among the top counties with the highest mortality and morbidity ranking compared to all others in the state. ${ }^{[7]}$

\subsection{Academic and community partnership}

The Health Wagon free clinic began in 1980 when a nurse practitioner began providing free health care to disadvantaged residents in Southwest Virginia out of her own Volkwagon Beetle, which came to be known as the "Health Wagon." Years later, the Health Wagon has evolved into a 501(3)c non-profit clinic, with a staff of ten; two nurse practitioners, five clinical support staff, three administrative support staff, and a local medical director who provides medical oversight. Today, as a result of federal grant support and generous donors, the Health Wagon serves patients at eleven different locations across Southwest Virginia using a mobile medical van, a stationary clinic, and a satellite specialty clinic. In addition, the Health Wagon collaborates with many other clinical enterprises to organize two Remote Area Medical (RAM) clinics that are held each year in the rural Appalachian Mountains of Southwest Virginia. ${ }^{[8]}$ These RAM clinics provide health care to thousands of patients, most of whom are unemployed (75\%) and/or uninsured $(62 \%)$, with almost half presenting with a chronic health condition that requires long term treatment. ${ }^{[9]}$

The UVA Health System, UVA Schools of Nursing and Medicine, as well as UVA-Wise have provided volunteers to the Health Wagon, particularly for the RAM events, for the past fifteen years. Historically, the travel distance has not been considered a significant barrier to UVA participa- tion in the large RAM events. These clinics require a fourday commitment to staff the 2.5-day clinics that occur at two locations (i.e. Wise and Grundy) once each year. Extensive planning and frequent contact, including meetings via telemedicine, is required among the partners over the course of each year prior to the events. Forged while planning these clinics, trusting relationships among key people who participated were integral when building a partnership to apply for federal funding to meet the overall goals of the proposed project.

\subsection{Project aims}

The specific aims of the educational component of the grant were to:

(1) Expand clinical training experiences for undergraduate, graduate and advanced practice nursing students at a rural free clinic with multiple mobile sites in an Appalachian region of Southwestern Virginia.

(2) Determine the feasibility of an academic and free clinic partnership model of clinical training for nurses, particularly graduate and advanced practice nurses, who are enrolled in the School of Nursing at a university located five hours away from the rural free clinics.

(3) Determine the successes, challenges and lessons learned over the three years of the grant, and disseminate the findings.

\section{Method}

\subsection{Procedures}

In the first year of the grant, a subcontract agreement was signed between UVA and the Health Wagon that outlined the agreement among the partners. The responsibilities of each partner are briefly summarized below.

UVA: School of Nursing (SON) project director had primary responsibility for monitoring nursing students' academic progress at all levels while they were receiving clinical training and experience at the Health Wagon. This included preparing students in Appalachian cultural sensitivity and humility, developing tele-health applications, and coordinating UVA Nurse Practitioner (NP), Clinical Nurse Leader (CNL), and undergraduate Bachelor of Science in Nursing (BSN) students' clinical rotations. NP students were in Family Nurse Practitioner or Acute Care Nurse Practitioner programs. The CNL students all had a bachelor's degree in a discipline other than nursing with direct entry into the MSN CNL program that prepared them with a generalist master's degree and eligibility to sit for the nursing board exam. SON faculty monitored students academic progress at all levels while they were obtaining clinical training and experiences. Feedback was solicited from the Health Wagon clinical preceptors for both students and program evalua- 
tion. Information was systematically collected on students and clinical practice sites. A SON coordinator was named to work with a Health Wagon Coordinator to determine and document the final hours, schedules and assignments.

The targeted number of UVA students to participate in the program was 38 graduate and 8 undergraduates each year, for a total of 114 students. The CNL students completed their graduate community health clinical with the Health Wagon. The NP students completed either a practicum or preceptorship with the Health Wagon in the fall or spring semester. In the summer, both CNL and traditional BSN students were scheduled to participate with the Health Wagon in the RAM clinics (see Table 1).

Table 1: Yearly targeted student enrollment

\begin{tabular}{|c|c|c|c|}
\hline \multicolumn{4}{|c|}{ Yearly Targeted Student Enrollment } \\
\hline & Fall & Spring & Summer \\
\hline \multirow{2}{*}{ Nurse Practitioner } & Practicum & Preceptorship & \multirow{2}{*}{0} \\
\hline & 2 students per 7 weeks $=14$ students & 2 students per 7 weeks $=14$ students & \\
\hline $\begin{array}{l}\text { Clinical Nurse Leader, } \\
\text { MSN community }\end{array}$ & 0 & 2 community clinical students & $\begin{array}{l}8 \text { community clinical } \\
\text { students at RAM }\end{array}$ \\
\hline $\begin{array}{l}\text { Traditional BSN or } \\
\text { RN-BSN }\end{array}$ & 0 & $\begin{array}{l}15 \text { UVA Wise students in } \\
\text { community clinical }\end{array}$ & $\begin{array}{l}8 \text { UVA students in } \\
\text { RAM elective }\end{array}$ \\
\hline $\begin{array}{l}\text { Total nursing students } \\
\text { undergraduate/ graduate }\end{array}$ & $0 / 14$ & $15 / 16$ & $8 / 8$ \\
\hline
\end{tabular}

UVA Wise: UVA Wise offers two undergraduate programs leading to a Bachelor of Science in Nursing (BSN); a direct entry pre-licensure program and a RN to BSN program. ${ }^{[10]}$ In collaboration with UVA Wise faculty, undergraduate nursing students were supervised by a NP at the Health Wagon as part of the wellness team.

The targeted number of UVA Wise nursing students was 15 per year, for a total of 45 . The nursing students participated in various specialty, RAM and local health fairs. A Health Wagon coordinator collected participation data as outlined by the UVA evaluator and provided the information to the UVA Project Director.

Health wagon free clinic: Two DNP prepared nurse practitioners were responsible for the on-site supervision of students from both UVA and UVA Wise during all Health Wagon operations. They provided students with an orientation of the practices and policies of the free clinic, communicated the health screening and competency requirements for student learning experiences and provided the facilities, equipment and supplies needed for the learning experience. UVA Wise students were individually scheduled for their clinical experiences at the HW. These experiences occurred on the mobile unit that traveled to designated areas three to five days each week and at the stationary free clinic. Clinical rotations were divided between the sites to optimize the clinical experience. A HW coordinator facilitated ongoing communication with the nursing schools at UVA and UVA Wise.

A UVA School of Medicine faculty evaluator from the Department of Public Health Sciences provided expertise in evaluation methods, data collection and supervised the biostatistician who conducted the final analysis of the data.

\subsection{Data collection, entry, and analysis}

Data were collected from all participating students using short structured forms. A form was completed before the start of the clinical rotation following the data and monitoring requirements of the HRSA grant. Demographic and educational data were self-reported by students and consisted of age, sex, family income, past education, and current education. The type of clinical completed was documented by the supervising clinician following the experience on a separate data monitoring form. Hard copy information from the HW was transferred to a research assistant at UVA who blindcoded the names and entered all data into an Excel spread sheet. Rural or non-rural background status was determined using the HRSA Office of Rural Health Policy and added to the database. ${ }^{[11]}$ Excel data were imported into SPSS 21 for the final analyses. Descriptive statistics were used in reporting numbers and percentages. Chi-square analysis was used in categorical comparisons. ANOVA was used to compare means among groups as appropriate.

\section{Results}

\subsection{Clinical training expansion}

The Health Wagon free clinic did not previously have a formal nurse training internship with an academic university except in a limited capacity for undergraduate nurses doing patient education. With funding from the HRSA grant, clinical training experiences for undergraduate, graduate CNL and advanced practice Family and Acute Care NP students were incorporated into the UVA SON curriculum and expanded to the Health Wagon clinic practice. Set schedules and protocols were developed with a focus on primary care 
in a rural setting, and supervision by both on-site DNP and UVA PhD SON faculty were jointly provided. A total of 145 undergraduate and graduate nursing students successfully participated in clinical training opportunities at the Health Wagon over the course of the three-year grant. Of the total students participating, $82.1 \%$ were female and $96.6 \%$ of students were non-Hispanic (only 5 were Hispanic). The majority of students were White, non-Hispanic (79.3\%); with 8.3\% $(\mathrm{n}=12)$ Asian, 6.2\% Black $(\mathrm{n}=9)$ and $6.2 \%(\mathrm{n}=$ 9) all others combined. Almost half (48.3\%) were undergraduate nursing students and $51.7 \%$ were graduate nursing students. Family income was reported by 120 of the students with 25 not reporting. Overall, most students $41.4 \%$ $(\mathrm{n}=60)$ reported average family income followed by $24.1 \%$ $(\mathrm{n}=35)$ reporting above average income, and $15.2 \%(\mathrm{n}=$ $22)$ who reported low family income. Only $2.1 \%(n=3)$ students reported high family income. About two-thirds of students $(67.6 \%, \mathrm{n}=98)$ reported residing in a non-rural location versus a rural location $(32.4 \%, \mathrm{n}=47)$. Of the 134 students who provided information on current residence, al- most all of the students $(89 \%, \mathrm{n}=129)$ resided in Virginia while 5 students $3.7 \%$ lived in other states. The majority of students $(80.7 \%, \mathrm{n}=117)$ reported they were still attending school.

Table 2 presents the socio-demographic results by type of student in the program. As expected, there were significant age differences among students. The average age of undergraduate nursing students was 22 years; compared with 29 years for graduate level students, and 36 years for advanced practice nursing students. An exploratory analysis, was conducted to compare the differences across the groups to inform potential improvements to the program. There were no significant differences across groups in gender, ethnicity/race, family income, being still in school, or residence. However, there were significant differences reported regarding whether the student was originally from a rural or urban location. Significantly more undergraduate students $(47 \%)$ than graduate $(0 \%)$ or advanced practice nursing students $(25 \%)$ reported a rural personal upbringing.

Table 2: Demographic characteristics of undergraduate, graduate and advanced practice nurses who received training in an academic and free clinic partnership ( $\mathrm{N}=145)$

\begin{tabular}{|c|c|c|c|c|}
\hline & Undergraduate & Graduate & Advance Practice & $P$-Value \\
\hline Total & $\mathrm{n}=70(48.3 \%)$ & $\mathrm{n}=19(13.1 \%)$ & $\mathrm{n}=56(38.6 \%)$ & \\
\hline Age (years) & $21.78( \pm 2.5)$ & $29.10( \pm 6.5)$ & $35.83( \pm 9.0)$ & $.001 *$ \\
\hline \multicolumn{5}{|l|}{ Gender } \\
\hline Female & $61(87.1 \%)$ & $13(68.4 \%)$ & $45(80.4 \%)$ & .15 \\
\hline Male & $9(12.9 \%)$ & $6(31.6 \%)$ & $11(19.6 \%)$ & \\
\hline Ethnicity/Race & & & & .77 \\
\hline White & $57(81.4 \%)$ & $14(73.7 \%)$ & $44(78.6 \%)$ & \\
\hline Black & $4(5.7 \%)$ & $1(5.3 \%)$ & $4(7.1 \%)$ & \\
\hline Asian & $6(8.6 \%)$ & $3(15.8 \%)$ & $3(5.4 \%)$ & \\
\hline Others & $3(4.3 \%)$ & $1(5.3 \%)$ & $5(8.9 \%)$ & \\
\hline Current Status & & & & .06 \\
\hline Still in School & $60(85.7 \%)$ & $14(73.7 \%)$ & $43(76.8 \%)$ & \\
\hline Graduated & $4(5.7 \%)$ & $4(21.1 \%)$ & $3(5.4 \%)$ & \\
\hline Not reported & $6(8.6 \%)$ & $1(5.5 \%)$ & $10(17.9 \%)$ & \\
\hline Family Income & & & & .11 \\
\hline Low & $8(14.5 \%)$ & $6(37.5 \%)$ & $8(16.3 \%)$ & \\
\hline Average & $31(56.4 \%)$ & $8(50.0 \%)$ & $21(42.9 \%)$ & \\
\hline Above Average & $15(27.3 \%)$ & $1(6.3 \%)$ & $19(38.8 \%)$ & \\
\hline High & $1(1.8 \%)$ & $1(6.3 \%)$ & $1(2.0 \%)$ & \\
\hline Residence & & & & .41 \\
\hline Virginia & $58(93.5 \%)$ & $19(100 \%)$ & $52(98.1 \%)$ & \\
\hline Tennessee & $1(1.6 \%)$ & $0(0.0 \%)$ & $1(1.9 \%)$ & \\
\hline Other States & $3(2.2 \%)$ & $0(0.0 \%)$ & $0(0.0 \%)$ & \\
\hline Rural Background & & & & $.001 * *$ \\
\hline Yes & $33(47.1 \%)$ & $0(0.0 \%)$ & $14(25.0 \%)$ & \\
\hline No & $37(52.9 \%)$ & $19(100.0 \%)$ & $42(75.0 \%)$ & \\
\hline
\end{tabular}

$* f(2,142)=79.6 ; * * \chi^{2}=17.49, d f=2$ 


\subsection{Feasibility of training nurses via long distant academic-free clinic partnership}

An academic and free clinic partnership model of clinical training for nurses, particularly graduate and advanced practice nurses, who are enrolled in a School of Nursing at a university located five hours away from the rural free clinics in partnership with a local college that trained undergraduate nurses was successfully developed. Overall, $51 \%$ (n $=74$ ) of nursing students spent their training assignment at the Health Wagon in Wise; 34.5\% $(n=50)$ reported being at the Wise RAM, and $14.5 \%(\mathrm{n}=21)$ reported being at the Grundy RAM. More than half of students $(62.1 \%)$ received clinical training over two to five days, $24.1 \%$ spent a day or less, and 9\% trained for more than 6 days. Table 3 shows the clinical training sites by length of time spent in supervised training by type of student. There was some missing data from students on times spent at training sites. Reli- able data were available for $97 \%$ of Undergraduates, $95 \%$ of Graduate, and $93 \%$ of Advance Practice nurses. There were significant differences found among groups.

Over half of the undergraduate student nurses $(64.3 \%)$ received clinical training at the Health Wagon, while $84.2 \%$ of graduate nursing students received clinical training at one of the RAM clinics. Advanced practice nurses received about the same training at the Health Wagon and the RAM clinics. Of interest, over half of the students $(63.1 \%)$ who were reared in urban areas received training at RAM events compared to $80.9 \%$ of students from rural areas, who were trained at the Health Wagon ( $\left.\chi^{2}=25.93, d f=2, p<.001\right)$. Rural students were more likely to be undergraduate students nurses attending UVA Wise. Overall, undergraduate student nurses $(45.6 \%)$ spent less than a day in training, compared to graduate and advanced practice students (94\%) who both spent a week or more in training (see Table 3).

Table 3: Location of clinical training site and time by student status

\begin{tabular}{lllll}
\hline & Undergraduate Nursing & Graduate Nursing & Advanced Practice & $P$-Value \\
\hline Clinical Site & $\mathrm{N}=70$ & $\mathrm{~N}=19$ & $\mathrm{~N}=56$ & $<.001^{* * *}$ \\
Health Wagon & $45(64.3 \%)$ & $3(15.8 \%)$ & $26(46.4 \%)$ & $18(32.1 \%)$ \\
Wise RAM & $17(24.3 \%)$ & $15(78.9 \%)$ & $12(21.4 \%)$ & $<.001^{* * * *}$ \\
Grundy RAM & $8(11.4 \%)$ & $1(5.3 \%)$ & & $3(5.8 \%)$ \\
Days in training & & $1(5.6 \%)$ & $44(84.6 \%)$ & $5(9.6 \%)$ \\
1 day or less & $31(45.6 \%)$ & $15(83.3 \%)$ & $2(11.1 \%)$ & \\
2 to 5 days & $31(45.6 \%)$ & & \\
6 or more days & $6(8.8 \%)$ & &
\end{tabular}

\subsection{Challenges and successes}

Some delays occurred in the first year of the grant due to the need to relocate the Health Wagon stationary clinic, which was originally in Clinchco to Clintwood, a town almost 40 minutes away. This move stemmed from safety issues related to increases in drug abuse and violence occurring in Clinchco, a small, former mining town of less than 400 residents tucked into a very remote steep mountain holler. ${ }^{[12]}$ The location became unsafe for both Health Wagon employees as well as students. Following the move, the clinical training resumed and more students were scheduled to meet program goals.

Since the Health Wagon functions as a working rural mobile clinic with multiple sites throughout the service area, flexibility was needed by both UVA and UVA Wise faculty in scheduling students within a structured academic environment to ensure on-site supervision and monitoring. Distance between the Health Wagon and UVA was somewhat of an academic barrier and the time commitment on the free clinic was more than was originally envisioned. Although travel costs for students were reimbursed, the time needed to travel between UVA and the Health Wagon may have prohibited more students, especially the advanced practice students, from participating. Rigorous academic schedules, work schedules, and time away from families may have also been a barrier to participation for students traveling from UVA to the Health Wagon. Students were also asked to self-report their household income, and many students were unsure how to categorize themselves.

\section{Conclusion}

Overall, academic and free clinic partnerships that train nurses of all levels, such as the one described are feasible. In this project, students from both urban and rural backgrounds successfully received training. However, success depends on commitment to the goals of the training, trust among all partners, an understanding of the time commitment, and ensuring that all partners are equal players in the process of implementation and participation in student evaluations.

\section{Acknowledgements}

HRSA Affordable Care Act Nurse Managed Health Clinics Grant number PO4CS22820. 
Publication of this article was funded in part by the University of Northern Colorado Pilot Fund for Faculty Publication.

\section{Conflicts of Interest Disclosure}

The author declares that there is no conflict of interest statement.

\section{References}

[1] Darnell, J. S. Free clinics in the United States: a nationwide survey. Archives of Internal Medicine. 2010; 170(11): 946953. PMid:20548006 http://dx.doi.org/10.1001/archint ernmed.2010.107

[2] Sefton, M., Brigell, E., Yingling, C., Storfjell, J. A journey to become a federally qualified health center. Journal of the American Academy of Nurse Practitioners. 2011; 23(7): 346-350. PMid:21696482 http://dx.doi.org/10.1111/j.1745-7599. $2011.00621 . \mathrm{x}$

[3] Fiandt, K., Doeschot, C., Lanning, J., Latzke, L. Characteristics of risk in patients of nurse practitioner safety net practices. Journal of the American Academy of Nurse Practitioners. 2010; 22(9): 474479. PMid:20854639 http://dx.doi.org/10.1111/j.1745-7 $599.2010 .00536 . \mathrm{x}$

[4] Bigbee, J., Mixon, D., Mixon, J. B. D. Recruitment and retention of rural nursing students: a retrospective study. Rural and remote health. 2013; 13(2486). PMid:24160687

[5] The Health Wagon. About Us. Available from: http://thehealt hwagon.org. 2014.
[6] Robert Wood Johnson Foundation and the University of Wisconsin Population Health Institute. County Health Rankings and Roadmaps, Virginia: Quality of Life. 2014. Available from: http://www. countyhealthrankings.org/app/virgi nia/2014/rankings/outcomes/overall.

[7] Robert Wood Johnson Foundation and the University of Wisconsin Population Health Institute. County Health Rankings and Roadmaps, Virginia: Length of Life. 2014. Available from: http://www. countyhealthrankings.org/app/virgi nia/2014/rankings/outcomes/overall.

[8] The Health Wagon. History. 2014. Available from: http://theh ealthwagon.org.

[9] Snyder, A. E., Milbrath, G. R. Description of healthcare needs at an episodic clinic in rural southwest Virginia. Rural and remote health. 2013; 13(2557).

[10] University of Virginia's College at Wise. Department of Nursing. 2014. Available from: http://www.wise.virginia.edu/nurs ing/.

[11] HRSA Office of Rural Health Policy. Designated eligible census tracts in metropolitan counties. 2010. Available from: $\mathrm{ftp}: / / \mathrm{ft}$ p.hrsa.gov/ruralhealth/eligibility2005.pdf .

[12] US Census Bureau. Clinchco, Virginia Population. 2010. Available from: http://censusviewer.com/city/VA/Clinchco. 